Revista de la red interuniversitaria de estudios sobre las literaturas rioplatenses contemporáneas en Francia

$23 \mid 2021$

La vereda de enfrente. Cruces entre las literaturas argentina y chilena del siglo XX

\title{
El secreto del nombre propio: Zama de Antonio di Benedetto y El obsceno pájaro de la noche de José Donoso
}

Le secret du nom propre: Zama de Antonio di Benedetto et L'Obscène Oiseau de la nuit

The secret of the proper name: Antonio di Benedetto's Zama and Donoso's The Obscene Bird of the Night

\section{Andrea Kottow}

\section{OpenEdition}

Journals

Edición electrónica

URL: https://journals.openedition.org/lirico/11539

DOI: 10.4000/lirico.11539

ISSN: 2262-8339

Editor

Réseau interuniversitaire d'étude des littératures contemporaines du Río de la Plata

Referencia electrónica

Andrea Kottow, «El secreto del nombre propio: Zama de Antonio di Benedetto y El obsceno pájaro de la noche de José Donoso», Cuadernos LIRICO [En línea], 23 | 2021, Publicado el 09 diciembre 2021, consultado el 07 enero 2022. URL: http://journals.openedition.org/lirico/11539 ; DOI: https://doi.org/ 10.4000/lirico. 11539

Este documento fue generado automáticamente el 7 enero 2022.

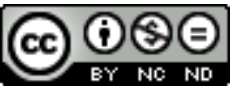

Cuadernos LIRICO está distribuido bajo una Licencia Creative Commons Atribución-NoComercialSinDerivar 4.0 Internacional. 


\title{
El secreto del nombre propio: Zama de Antonio di Benedetto y El obsceno pájaro de la noche de José Donoso
}

\author{
Le secret du nom propre: Zama de Antonio di Benedetto et L'Obscène Oiseau \\ de la nuit \\ The secret of the proper name: Antonio di Benedetto's Zama and Donoso's The \\ Obscene Bird of the Night
}

Andrea Kottow

\section{Dos hombres, dos vidas, dos obras}

1 Ambos nacieron en la década del 20' del siglo pasado. Antonio de Benedetto en 1922, en la ciudad argentina de Mendoza; en 1924, José Donoso, en Santiago de Chile. Los dos vivieron varios años fuera de sus países natales. Di Benedetto salió de Argentina en 1977; vivió en Francia y luego en España, en su capital Madrid. José Donoso hizo, primeramente, una serie de salidas breves de Chile; estuvo entre 1958 y 1960 en Buenos Aires; unos años más tarde se instaló en México, y salió por un período más largo el año 1967, residiendo en diversas ciudades de España, instalándose, asimismo, entre 1978 y 1980 en Madrid. Ambos usaban lentes de marcos gruesos, a la usanza de la época, para compensar sus miopías. Y los dos llevaban bigote y barba (algo más nutrida la de Di Benedetto), el pelo más bien largo, peinado hacia atrás, exhibiendo sus amplias frentes. Di Benedetto muere en 1986, diez años antes que Donoso. Los dos ya habían vuelto a sus países de origen. José Donoso regresa a Santiago de Chile el año 1981, aún en plena dictadura, y Antonio de Benedetto vuelve a Argentina en 1984, ya recobrada la democracia ${ }^{1}$.

2 Ambos autores pertenecen a la misma generación literaria y son contemporáneos de los escritores que popularizan la literatura latinoamericana para el resto del mundo. José Donoso como un autor satélite del boom; amigo íntimo de algunos de sus grandes 
representantes -Carlos Fuentes y Mario Vargas Llosa-, y conocido de varios más, como Gabriel García Márquez; y Di Benedetto en tanto cultivador de una escritura de tonos más tenues. En una columna publicada el año 2017 en El País por Jimena Néspolo autora del libro Ejercicios de pudor. Sujeto y escritura en la narrativa de Antonio Di Benedettoes puesto al lado de otros autores, como Juan Rulfo y María Luisa Bombal, como escritores adscritos a un anti-boom.

3 Ególatra insuperable uno, siempre pendiente tanto de sus propios éxitos como también envidioso de los aplausos recibidos por aquellos que lo rodeaban -Donoso, sin lugar a duda, hubiera dado mucho por pertenecer a la primera liga del Boom-, personaje más humilde y derrotado el otro: Di Benedetto muere solo y pobre, en su propia ley. A pesar de haberse ganado varios premios literarios importantes, el éxito no parece haber sido lo que movía a este último. Donoso no dejó de pensar nunca en los suyos, obsesionándose con los galardones literarios (de los cuales muchos de los más anhelados nunca le fueron otorgados), con las reseñas, con los éxitos de venta, con la presencia o ausencia de sus obras en los escaparates de las librerías.

4 Di Benedetto vivió exiliado de su Argentina natal, y antes de salir del país estuvo preso y fue torturado. A Donoso, muchos le solían echar en cara que nunca se comprometió políticamente y solo tardíamente hizo declaraciones más explícitas que mostraban su postura adversa frente a la dictadura militar. No fue un exiliado político; fue un hombre perteneciente a la elite chilena que se casó con María Ester Serrano, más conocida como María Pilar Donoso, alguien que aportaba a la posición social a la que Donoso tanto aspiraba, y que salió de Chile porque le parecía que esta larga y delgada franja de tierra al sur del mundo le quedaba chica.

5 Zama (1956) es considerada por muchos como la obra maestra de Di Benedetto, un hombre que, si bien se dedicó toda la vida a las letras, no fue muy prolífico, al menos si se considera la cantidad de sus publicaciones. Autor de un puñado de novelas, de las que suelen destacarse, además de su obra maestra Zama, El silenciero (1964) -una novela que recrea de forma irritante el acoso que un neurótico sufre por ruidos molestos en su entorno, huyendo de casa en casa en búsqueda del silencio- y Los suicidas (1969), un texto que gira en torno a la muerte y la especulación en torno al carácter hereditario del suicidio. Autor aplaudido por sus cuentos, Antonio di Benedetto publicó otros tantos volúmenes con sus relatos más breves.

Donoso, en cambio, cuenta con la autoría de más de una decena de novelas, varias de ellas muy conocidas -Coronación (1957), Este domingo (1966), El lugar sin límites (1966), Casa de campo (1978), El jardín de al lado (1981)- además de haber incursionado en otros géneros, como con el ensayo Historia personal del boom (1972), o sus aproximaciones al teatro y al cine. Si bien puede no haber consenso con relación a lo que sería su mejor novela, sí suele ser preponderante la opinión de que El obsceno pájaro de la noche (1970) es su obra más compleja. Es, además, un texto que para Donoso siempre fue un referente en su propia escritura. En sus diarios, retomados por su hija Pilar Donoso en el desgarrador testimonio Correr el tupido velo, el autor vuelve una y otra vez al obsceno pájaro, a la experiencia de su escritura, como si funcionara para él como la cúspide de su quehacer escritural y la máxima expresión de un encuentro con su labor en tanto artesano del lenguaje.

7 Zama fue escrita por Di Benedetto en tan solo un mes. Donoso estuvo luchando con la escritura de El obsceno pájaro por más de siete años. Experiencia retomada en numerosas ocasiones, Donoso se sintió muchas veces entrampado con su trabajo en la novela. Se 
desesperaba por no ver el norte, por no saber dónde ubicar ciertos episodios, qué hacer con algunos personajes, cómo desenredar esa extraordinaria madeja de identidades, lugares, figuras, pesadillas que pueblan el texto. Solo el despertar de las fiebres sufridas por una reacción alérgica a la morfina que le propinaron para aplacar los dolores por un ataque de úlcera, en las que imaginó que las enfermeras lo envenenaban y sacaban la sangre con fines de traficarla, le hicieron poder ver el final del túnel de su obra.

Di Benedetto, tal como propone Julio Premat, puede entenderse como un escritor de la borradura, de la "reducción y reflejo miniaturizado" (2017: 22), mientras que, en contraposición, Donoso es un autor del derroche y del exceso. Menos es más, en el argentino; por el otro lado, más pareciera siempre ser más, en Donoso.

9 Se podrían seguir anotando semejanzas y, las mas de las veces, diferencias entre estos dos autores que provenían de países vecinos y que se formaron literariamente en la misma época. Pero más allá del valor anecdótico que pudiese tener este ejercicio, quisiera con ello abrir una vía de exploración conjunta de sus obras, las que, si bien han sido ampliamente atendidas por la crítica y han recibido profusa recepción crítica, contando con lecturas e interpretaciones brillantes, no han sido leídas una en relación con la otra.

\section{Acerca del secreto}

10 El recorrido que quisiera proponer para Zama y El obsceno pájaro como dos novelas cuya lectura entrecruzada puede iluminar zonas menos visibilizadas hasta ahora por la crítica, pasa por pensar lo que puede ser denominado el secreto del nombre propio. Los dos textos articulan sus complejas tramas, que rayan a ratos en el delirio y lo pesadillesco, a partir de una serie de secretos.

Quisiera pensar el secreto desde dos aristas que, en algún punto, se contradicen, pero que, al mismo tiempo, se potencian. La primera idea tiene que ver con lo que plantea Ricardo Piglia cuando entiende el secreto como algo que alguien sabe, pero no revela. Para llegar a esta definición, Piglia diferencia entre el enigma, el misterio y el secreto como formas que configuran distintos tipos de narraciones o, dicho de otra manera, que articulan las tramas y organizan la información dentro de ellas. El enigma apunta a "la existencia de algún elemento -puede ser un texto, una situación- que encierra un sentido que se puede descifrar" (2015: 249). En cambio, en el misterio estaría puesto en juego un fenómeno que no puede recibir una explicación según las lógicas imperantes en el mundo habitual. Para el secreto, Piglia propone que "se trata también de un vacío de significación, es algo que se quiere saber y no se sabe, como el enigma y el misterio, pero en este caso es algo que alguien sabe y no dice" (249). Sería acá, entonces, un saber que se oculta con cierta voluntad y determinada intención.

Lo secreto es un motor que modula a los personajes de un relato en torno al saber y al no saber, y al poder que ese conocimiento porta consigo. Poder para destruir o para salvar: es un saber que se entreteje de forma indisoluble con un poder que ese conocimiento contiene.

Claudio Magris acentúa la importante relación entre secreto y poder. Este último se erigiría sobre la base de un saber que tiene quien ostenta el poder, y que guarda para asegurarlo. Mantener en secreto algo frente al otro otorga poder a quien tiene ese saber. Escribe Magris: "Guardar el secreto. El secreto y su custodia son un elemento 
fundamental de la potencia, del poder" (2017: 9). Si el poder necesita de lo secreto para su fundamentación, también teme los secretos de los otros. El secreto es, así, tanto sustento de poder como su mayor amenaza. Es un arma de doble filo; puede servir para acrecentar el poder, pero, a su vez, también para hacer peligrar sus bases. Esta mutua determinación entre secreto y poder emerge en las dos novelas analizadas aquí. En otras palabras, el hecho de hacer girar las historias en torno al secreto implica a su vez una pregunta por el poder: el poder de la tradición, de la historia, de la conformación de lo social y de su genealogía, de la política y de los poderosos, y la pregunta por las posibilidades de escabullir de él.

La segunda idea de secreto que podría pensarse al otro costado de la definición ofrecida por Piglia, sería el planteamiento de aquello que Jacques Derrida llama el secreto absoluto. En una entrevista que le hace Mauricio Ferraris, publicada luego en $\mathrm{El} \mathrm{gusto} \mathrm{del}$ secreto, Derrida defiende una idea de secreto que se relaciona con su imposible revelación. Propone un secreto pensado desde su máxima radicalidad. Para él y su idea de escritura siempre habría algo que se escapa a su nombramiento, que no puede ser recogido en el lenguaje. Sin embargo, sería su condición de posibilidad, por lo tanto, el único lugar desde donde rozar ese secreto, hacer que pueda ser atisbado, es la escritura. La búsqueda derridiana por poner en cuestión los límites que separan una escritura propiamente filosófica, por un lado, y una de carácter literaria y autobiográfica, por el otro, atraviesa varias de sus obras. El asunto que, entre otros, se juega ahí dice relación con lo teórico/general/sistemático, por un lado, y lo literario/particular/personal por el otro. La literatura, en esta contraposición, ocupa el lugar de un decir que puede acoger en sí la duda, soportar la incertidumbre y dar cuenta de un secreto irrevelable, sin negar su existencia. Al reflexionar sobre las diferencias entre filosofía y literatura, Derrida pone en juego la noción de traductibilidad, postulando que habría una demanda de la filosofía de hacer posible, sin mayor pérdida, la traducción de una lengua a otra, mientras que en la literatura permanecería siempre una dimensión que no puede ser traducida y que se debería a otro tipo de vínculo con la lengua original en la que fue concebida la obra: "algo [en la literatura] estaría destinado a resistirse a la traducción, en tanto que en aquello que llamamos 'filosofía' lo esencial estaría destinado a dejarse traducir e incluso a posibilitar la traducción: esto equivale a decir que cuanto hay de traducción en la literatura sería filosófico y cuanto queda intraducible sería más estrictamente literario" (2009: 67). Habría algo en la manera en que la literatura despliega su decir y sus verdades que colinda con lo secreto en su dimensión más radical; en lo que no puede recibir nombre. Pues aquello que se estaría diciendo y que no puede ser traducido, precisamente no se agota en lo que se dice, en su contenido. Es así, que Derrida establece un vínculo estrecho entre literatura y secreto, donde lo propiamente literario es atravesado por lo secreto.

15 Tanto Zama como el Obsceno pájaro ponen en juego en su despliegue una noción de lo secreto que va más allá de lo silenciado u ocultado. En el mismo lenguaje habría algo que se resiste a su transparencia, volviendo opaco todo intento de explicación última o unívoca. El lector queda atrapado en una red de signos que evidencia la imposible correspondencia entre lo real y el lenguaje que lo intenta capturar. Ese resto que se escabulle -inatrapable, innombrable- emerge entre las líneas de estas dos novelas, volviendo a ratos ominosa la experiencia de lectura. Lo que propongo en estas páginas es una aproximación tentativa a ese secreto del nombre propio, pues en este se haría evidente la naturaleza siempre divergente del lenguaje con relación al mundo y los objetos que lo pueblan. El nombre propio no hace sino referir a algo imposible de fijar 
en un significado. En tanto forma de significante puro, el nombre remite al lenguaje mismo.

\section{La pregunta por el porvenir}

Novela de la espera, del tiempo que parece no transcurrir, no obstante, engulle la existencia de su protagonista: Zama, la novela que Antonio Di Benedetto publica el año 1956, es un texto que nos hace reparar en las formas en que habitamos el tiempo y el espacio, que indefectiblemente se convierten en experiencias del yo. Paisajes interiores que revelan nuestros deseos y fantasmas, en un vaivén continuo entre lo interior y el exterior y nuevamente del afuera hacia el adentro.

La trama de la narración transcurre en la última década del siglo XVIII -en una subdivisión temporal tripartita que se sitúa en 1790, 1794 y 1799 respectivamente-, en Asunción del Paraguay ${ }^{2}$. El protagonista de la historia se encuentra alejado de todo centro político y administrativo, y lejos de su familia: Don Diego de Zama, un funcionario criollo de la corona española. Está sumido en la espera; una que anhela el reencuentro con su esposa Marta y sus hijos, el traslado a Buenos Aires, acaso incluso a la España imperial, la salida de ese espacio y tiempo que amenazan continuamente con imponerse como un no-tiempo y un no-espacio.

La novela está dedicada a las "víctimas de la espera". Tiempo paradójico el de la espera, que hace sentir el tiempo como quizás pocas otras experiencias. Quien espera quiere que el tiempo pase rápido, para que aquello que es esperado llegue lo antes posible. Se pretende, de alguna forma, burlar la lógica misma del tiempo, que es inmutable a nuestras voluntades. Pero, a su vez, la espera hace que aquello esperado se encuentre más lejos que nunca. Pues ese presente, que insiste e insiste sin pasar, sin acercar al futuro imaginado como plenitud, no hace más que hacerse pesado, resistiéndose a su transcurrir. Esperar es sentir el tiempo y desear que no exista. Esperar es querer convertir el presente en pasado, y el futuro en presente. Esperar es el deseo de poder jugar a ser Cronos, devorando el tiempo de la propia existencia. La espera habita tan solo el tiempo de la espera: nostalgia y ansiedad, superposición de una mirada atrapada en el pasado y situada en el futuro. Esperar claudica el presente con la única ambición de que este deje de ser. Tal como escribe Roland Barthes sobre la espera amorosa, esta tiñe de un halo irreal al entorno: "La angustia de la espera no es continuamente violenta; tiene sus momentos apagados; espero y todo el entorno de mi espera está aquejado de irrealidad [...]" (1997: 124).

Despojado del tiempo, Zama se mueve como una especie de espectro por un espacio que apenas adquiere contornos para el lector. Un espacio que carece de subdivisiones, de centro y sus alrededores, de hitos que lo vuelvan clasificable, mapeable. Se trata de un lugar, que, en la ausencia de descripciones, de lo que se constituye como imposibilidad de ser descrito, remite a una cierta interpretación acerca de la historia colonial. Una historia que no termina por hacer sentido, que se atraviesa por figuras que suponen representan algo -autoridad, poder, saber-, pero que no dejan der ser pálidos fantasmas de sí mismas. Un espacio abierto, pero vacío, que no está disponible para inscripciones que permitan generar significación. Pálidas y artificiosas imitaciones del centro, los espacios recreados son piezas expulsadas del tablero y del juego en el que harían sentido ${ }^{3}$. 
Jimena Néspolo recrea, en su estudio de la novela, los episodios históricos que sirvieron a Di Benedetto como pretexto (entendido no como excusa, sino como la existencia de una serie de coordenadas previas a la escritura de Zama). Uno de ellos dice relación con la Real Ordenanza de Intendentes que fuera dictada en Buenos Aires en 1782, según la cual las intendencias venían a sustituir el sistema antiguo de corregimientos, eliminándose, consecuentemente, los cargos de corregidor y gobernador. Uno de los efectos de estas medidas es que los cargos que podían ser antaño ocupados por criollos, ahora pasan a ser responsabilidad de los intendentes que debían ser funcionarios de la misma metrópoli. Esta disposición debía servir a la mejor administración de las colonias, restándole simultáneamente poder y alcance a los criollos, que se veían marginados y suplantados por funcionarios peninsulares. Diego de Zama es "uno de estos criollos desplazados por la reforma" (Néspolo 2004: 261).

Al comienzo de la novela, arriba un barco -siempre esperado por Zama- pues podría traer noticias de Buenos Aires o incluso de España, del mismísimo Rey. Noticias de su mujer y acerca del futuro. Noticias que podrían anunciar el anhelado traslado. En lugar de aplacar la espera de Don Diego, el barco ha traído a un antiguo amigo suyo, el oficial Indalecio Zabaleta, quien viene con su hijo. El padre le presenta a Don Diego con solemnidad: "En el viaje le he dicho quien era el doctor don Diego de Zama" (Di Benedetto 2002: 19). La narración, relatada en primera persona por su protagonista, se interrumpe, para hacer hablar a Don Diego de sí mismo en tercera persona. Este desdoblamiento al cual se somete el personaje, que lo divide en dos Zamas, uno del presente y otro del pasado, funciona como marca textual del despojamiento del protagonista. Ni acá ni allá, ni ahora ni antaño; Zama no se reconoce ni en su pasado ni se halla en su presente, sino habita la escisión. Una que rodea su nombre con un halo fantasmal y que le hace no reconocerse en el nombre propio.

¡El doctor don Diego de Zama!... El enérgico, el ejecutivo, el pacificador de indios, el que hizo justicia sin emplear la espada. Zama, el que dominó la rebelión indígena sin gasto de sangre española, ganó honores del monarca y respeto de los vencidos. No era ése el Zama de las funciones sin sorpresas ni riesgos. Zama el corregidor desconocía con presunción al Zama asesor letrado, mientras éste se esforzaba por mostrar, más que un parentesco, cierta absoluta identidad que aducía. [...] A esta altura del duelo, Zama el menguado podía sospechar que Zama el bravío no tuvo tanto de aguerrido y temible: un corregidor de espíritu justiciero puede seducir fácilmente la voluntad de esclavos estragados por meses de represión más que violenta, cruel. (20)

Frente a la admiración que el niño le profesa, inspirado por los relatos que ha recibido de su padre, la mirada que el propio Zama posa sobre sí mismo tiende a desdibujar la figura heroica que le llega desde su pasado. Por un lado, porque el presente y sus funciones ya no requieren de ningún tipo de destreza más que poder aguantar el sopor que las tareas actuales provocan en él. Sin nada que pueda interrumpir una calma que no esconde sino inactividad y estancamiento, Zama el corregidor, el asesor, está sumido en un presente que se impone como un tiempo cero, que no se colma de ninguna acción ni sentido. Por el otro lado, porque aquella imagen del Zama pacificador, se derrumba frente a sus propios ojos. Más que haber logrado que los indios derrotados lo admiraran por el respeto que les merecía, Zama reconoce que la entrega del enemigo vencido se debió a que fueron victimizados con violencia y alevosía por un tiempo prolongado y así quedó domesticada cualquier pulsión rebelde. 

presente no es nadie, pues no hace nada y no hay nada que hacer; tampoco vive de los recuerdos de un pasado glorioso, pues él mismo los ha deconstruido. La reiteración, casi obsesiva, del nombre Zama en la cita de más arriba, en lugar de asegurar una identidad, más bien tiende a desdibujarla ${ }^{4}$. Como cuando, de tanto repetir una palabra, dejamos de reconocerla y esta sufre un efecto de desnaturalización, subrayando el carácter arbitrario, incluso absurdo, de la relación de una palabra con aquello que nombra. ¿Quién o qué es Zama? ¿Qué se esconde detrás de esas cuatro letras que de tanto multiplicarse producen un efecto de irrealidad? Si se suprimen los sustantivos que puntualizan los cargos ocupados por Zama y los adjetivos que siguen al nombre y que van destacando ciertos rasgos, no queda nada más que un puñado de letras que no sabemos qué significan o pudiesen contener. La paradoja del nombre propio reside en que si no se apega de manera absoluta a quien lo lleva, pierde cualquier posible sentido ${ }^{5}$. inicio, se encuentran en los buques que arriban al puerto y que traen cartas. Estas correspondencias condensan la posibilidad de huir de este tiempo y espacio suspendidos; el traslado a Buenos Aires, a la ciudad donde está su familia y donde se encuentra el centro administrativo del virreinato, se le presentan a Zama como las fugas de su existencia actual. El porvenir se le muestra desde la extraña potencialidad de convertirse en quien pudo haber sido en el pasado: “Tal vez ese Zama que pretendía parecerse al Zama venidero se asentaba en el Zama que fue, copiándolo, como si arriesgara, medroso, interrumpir algo" (Di Benedetto 2002: 21). Crisol del tiempo, ese punto imposible que anhela Zama conciliaría todos los tiempos, y haría que pasado, presente y futuro se encontraran en armonía; pero justamente reparar en su división implica que esta coincidencia no es sino un horizonte ansiado. El nombre propio se halla expulsado de sí mismo, dejando de significar algo y volviéndose el gran secreto que ni el propio Zama logra descifrar.

Desde las primeras escenas de la novela, el relato se colma del deseo de Diego de Zama, un deseo sensual que lo subyuga, lo hace sufrir y, una vez más, lo escinde. La novela se abre con el personaje escondido entre la frondosa vegetación espiando a un grupo de mujeres mulatas que se bañan desnudas en las orillas del agua. "No quise seguir mirando, porque me arrebataba y podía ser mulata y yo ni verlas debía, para no soñar con ellas, y predisponerme y venir en derrota" (12). Las mujeres notan la presencia del hombre y cuando este huye, para develar su identidad, una de ellas lo persigue hasta alcanzarlo. El hombre reacciona con violencia y golpea a la mujer. Deseo reprimido por ser uno que se posa en cuerpos otros, indios, y que se troca en brutalidad. Zama le pega a la mujer, pero de alguna forma es una violencia que ejerce sobre sí mismo, por no hallarse en su deseo.

Otra mujer que acapara la atención del protagonista es la española Luciana Piñares, esposa del ministro. Sueña con relaciones extramaritales, pues la infidelidad se la aparece como una aventura que logra burlar las normatividades que organizan lo social: "Ningún hombre -me dije- desdeña la perspectiva de un amor ilícito. Es un juego, un juego de peligro y satisfacciones. Si se da el triunfo, ha ganado la simulación ante interesado tercero y contra la sociedad, guardiana gratuita" (29). Nunca se consuma este anhelo de Zama; Luciana Piñares alimenta sus esperanzas, pero solo para escabullírsele una y otra vez. El deseo por la española se entremezcla con el deseo por

Cuadernos LIRICO, 23 | 2021 
Rita, otra mujer que juega con las miradas deseosas de don Diego, diluyéndose entre las diversas figuras femeninas -mulatas cuyos cuerpos declara le producen repugnancia; Marta, su mujer, que habita sus recuerdos; Rita, que busca la protección de Don Diego para vengarse de quien ha abusado de ella; Luciana de Piñares, la española de cuerpo blanco- solo para verse desplazado una y otra vez. "Esa noche soñé que por barco llegaba una mujer solitaria y sonriente, sólo para mí, necesitada de mi amparo, que se confiaba a mis brazos y mezclaba con la mía su ternura. Pude precisar su rostro, gentil, y un vello rubio que le hacía durazno el cuerpo y me ponía goloso. No era Marta; tampoco Luciana. No era nadie que yo conociese" (43).

El objeto de deseo de Zama muestra las contradicciones y sus imposibles resoluciones que habitan al protagonista. Las indias son tan prohibidas para el corregidor criollo como las blancas españolas. El anhelo por los cuerpos indígenas podría ser leído desde la cifra de la conquista y de la posesión. Son cuerpos que, según la lógica colonial, le pertenecen al conquistador. Los cuerpos morenos de las indias son, para el conquistador europeo, exóticos; su atractivo erótico y sexual emerge de su otredad, del gusto por lo extranjero y lo desconocido. Pero, recordemos, Zama es criollo. Para la lógica que le aplica, son cuerpos que le están vedados, que debe ignorar en su atractivo. Algo similar ocurre con los cuerpos blancos de las españolas, exclusivamente disponibles para peninsulares. La "economía de los cuerpos" (1999) -la expresión es de Gayle Rubin- organiza el acceso a los cuerpos, administra a los sujetos y los objetos del deseo. Zama, despojado de la posición social que solía otorgarle poder, perdido en un espacio que pierde su legibilidad, expulsado del significado de su nombre, extraviado entre deseos imposibles, va a la deriva, una que amenaza con perderlo para siempre. Zama se ve atrapado en una red de deseos incumplidos, generándose el despojo de sí, experiencia reiterada entonces en el habitar de un espacio imposible de trazar; un tiempo, donde el presente solo adquiere sentido por acercar a un futuro que no obstante no termina nunca de llegar; y un deseo que solo se vive desde el continuo desplazamiento.

Zama es una novela del despojo: el personaje va decayendo en la medida en que el tiempo transcurre sin traer nada de lo que él espera. La trama cierra con el protagonista al borde de la muerte, con las alucinaciones de su agonía, prisionero de Vicuña Porto, quien ha traicionado a la corona. Este opera como una especie de doble de Zama. Porto se ha convertido, en este mundo, del que todo indica que hay nada que esperar, en una especie de pistolero que trabaja para sus propios intereses. Como Porto es buscado por las autoridades, se esconde, se transmuta, se enmascara. Niega su nombre y su identidad. Vacía el nombre propio de cualquier posible sentido, siendo así una figura que refleja al protagonista. A Zama le dice: "No existe el Vicuña Porto ni lo soy yo ni lo es nadie. Es un nombre. Y el mío es Gaspar Toledo. Soy Gaspar Toledo, un año largo llevo siéndolo, y no quiero ser otra cosa" (Di Benedetto 2002: 241). El nombre propio deviene en un sinsentido, pues nada queda atado a él. No hay vínculo entre el nombre y la persona que lo encarna; la palabra no toca al cuerpo. El nombre propio se vacía y se convierte en el secreto absoluto que encierra algo imposible de revelar y que pierde relación con al asentamiento de una identidad que pueda ser capturada por medio de la razón. Secreto que se apega al significante y cuestiona así las condiciones de posibilidad para la emergencia de un significado.

Los hombres de Vicuña Porto buscan, desesperadamente, los Cocos que deben hacerlos ricos. Por ello, es que le han perdonado la vida a Zama, para que él los guíe al lugar de 
su futura riqueza. Cuando este les dice que los Cocos no tienen valor alguno, y se encuentra con la estupefacción de ellos, Zama responde con una oración que sirve como puerta posible de entrada a toda la novela: "[...] hice por ellos lo que nadie quiso hacer por mí: decir, a sus esperanzas, no" (258). El tiempo ha transcurrido -son casi diez años los que están contenidos en la trama de la novela-, y finalmente ha quedado derribada la ilusión, esa peligrosa contracara de la espera.

La pregunta por el porvenir que encierra la novela de Di Benedetto, en tanto una que no solo involucra a Zama, su personaje principal, sino una interrogante por el devenir de un espacio colonizado, de un territorio suspendido, se termina por cifrar en un secreto: uno que gira en torno al nombre propio que se eclipsa en un sentido en fuga. El cierre de la novela parece más bien pesimista en torno a las posibilidades de una ilusión encerrada en lo que permanece oculto. El final puede ser conectado con la imagen que da inicio al texto, en la cual un mono muerto vaivenea en el agua:

Con su pequeña ola y sus remolinos sin salida, iba y venía, con precisión, un mono muerto, todavía completo y no descompuesto. El agua, ante el bosque, fue siempre una invitación al viaje, que él no hizo hasta no ser mono, sino cadáver de mono. El agua quería llevárselo y lo llevaba, pero se le enredó entre los palos del muelle decrépito y ahí estaba él, por irse y no, y ahí estábamos." (9)

Desgarradora imagen, la de este mono muerto que Zama reconoce como su alter ego anticipando su propio fin. La espera no llega si no a su culminación en la muerte, en el viaje último. El viaje, el traslado, el movimiento es lo que alienta la espera en su acepción de esperanza, de cambio y transformación. Pero acá este impulso renovador es suplantado por el flotar de un cuerpo muerto en aguas que no permiten la partida.

En sus disquisiciones acerca del secreto, Luisa Valenzuela hace una distinción entre lo que ella denomina los secretos cotidianos, pequeños, inocentes. Esos secretos que, en la aproximación de Piglia a la que refería al comienzo de estas líneas, están contenidos en un saber que alguien tiene, pero calla. La escritora está más interesada en lo que subraya con la escritura de la S mayúscula, en el Secreto. Ahí, siguiendo a Derrida, el Secreto está atado a lo inefable, a lo que no podemos atravesar con las palabras, sino apenas rozar con ella. Se trata del Secreto de la vida y la muerte, de lo que podría revelarnos el fin último de todas las cosas, de lo que tocaría aquello que no podemos alcanzar a través del orden simbólico, lo que en términos psicoanalíticos de Lacan se denomina la Cosa (otra vez aparece esa mayúscula que transgrede las reglas gramaticales para acentuar sus insuficiencias). El Secreto, así, está indisolublemente entretejido con la presencia imposible de la muerte. Retomando a Derrida, Valenzuela propone: '"El secreto del secreto', dice Derrida en Donner la mort, 'reside en que no se trata de conocerlo y que está allí para nadie', pero su presencia es ardiente y el animal humano, desde siempre confrontado con el misterio de la vida, atento a la propia mortandad, hierve en su caldero" (Valenzuela 2003: 15).

El secreto del nombre propio en Zama empieza y termina, como el uroboro que se come su propia cola, en la muerte. El secreto del significado, del sentido, de lo que está contenido en aquello que permanece, a pesar de todos los esfuerzos, oculto. La literatura es una manera de acercarse, de vislumbrar, de asomarse a ese secreto. El secreto de Zama, el hombre, y Zama, la novela, transita del nombre propio al tiempo y al porvenir, al espacio, a la historia colonial; transita de la vida a la muerte y de la muerte a la vida. 


\section{La trampa del pasado}

En muchos sentidos, un texto que podría operar de forma contraria a Zama, El obsceno pájaro de la noche de José Donoso, publicado en 1970, remite a lo cerrado. Si en Zama predomina el descampado y la imposibilidad de cercar y mapear el territorio que le sirve de trasfondo, en la obra de Donoso todo parece encierro y clausura. Novela claustrofóbica, cuya trama se juega entre dos casas: La Rinconada, una gran casa de campo perteneciente a la familia de los Azcoitía, y la Chimba, un ex-convento transformado en un continente laberíntico y ruinoso habitado por las así llamadas "viejas". En el mundo configurado por Donoso es el pasado el que insiste en perpetuar sus condiciones; el presente está atrapado en sus coordenadas y, de esta forma, se cierra, también, a todo porvenir. Cualquier posibilidad de escabullir las fauces del pasado resultan vanos aleteos que no permiten escapar de los fantasmas de antaño, vinculados a las violencias inscritas en la historia de Chile. Como propone Álvaro Bisama en su prólogo a la novela: “[...] Donoso trata acá de descifrar el orden secreto del país, proponiendo a la literatura como una herramienta para comprender su trama secreta" (2016: 13). En este sentido, y he ahí un paralelo potente y desatendido entre Di Benedetto y Donoso, habría en el Obsceno pájaro una interpretación de la historia, de la conformación de las naciones de América del Sur, que se muestra marcada por violencias cuyas cicatrices no se cierran.

Las relaciones entre amos y sirvientes, blancos e indios, colonizadores e indígenas, aristócratas y pobres, poderosos y despojados son las que tejen toda la trama de la novela. La serie de los patrones, los dueños no solo de las tierras y de las casas, sino también de todos quienes habiten en ellas, se pretende libre y limpia de una mezcla con la otra serie. Los sirvientes forman parte necesaria del paisaje, pero no deben sino obedecer a las estrictas órdenes de los amos. Sin embargo, se produce, una y otra vez, la superposición. Cuando esta ocurre, se difuminan las líneas divisorias entre ambas series y adviene la catástrofe. Esta, en el Obsceno pájaro, remite al monstruo, figura inclasificable, que se resiste a entrar en serie. Resultado de la mixtura de las dos series, el monstruo Boy es el que, por su monstruosidad, ocupa un lugar marginal a las series. Los monstruos no pueden sino formar serie con otros monstruos, donde lo único que tienen en común, es su monstruosidad. Conjunto paradójico y paralógico, la serie de los monstruos es, al mismo tiempo, una serie imposible, pues está marcada por la diferencia como único rasgo compartido. Una diferencia que se cifra asimismo en un nombre que parece la transcripción de la palabra "niño" al inglés, como si ningún nombre pudiese contenerlo. No es sino un Boy, un niño desviado, anómalo, que no calzará jamás con un nombre que pueda explicarlo o interpretarlo, y que por ello solo se puede nombrar con una descripción. Pero una que le es sonsacada a otra lengua, a una extranjera. Boy no solo encarna el secreto de sí mismo, de ese nombre que no existe, sino también el secreto de la mixtura de ambas series, de una paternidad que nunca se resolverá, y de una maternidad que se estrella contra la infertilidad de la supuesta madre. Un nacimiento que fue posibilitado por un pacto fáustico, cuyas dimensiones se llevará el mudito, convertido en imbunche, a la tumba.

La superposición de ambas series a la vez trae como consecuencia las confusiones identitarias: Jerónimo de Azcoitía, el patrón, tiene su doble en Humberto Peñaloza, el mudito, su secretario, el escribiente. Inés, su hermosa mujer, se duplica en Peta Ponce, su criada, su madre sustituta, quien se encarna en la perra amarilla, fuerza oscura y 
mitológica, que amenaza el aparente orden de las cosas. Madre sustituta pero también madre sustituyente, pues es quien presta su fertilidad a su patrona para que esta pueda embarazarse. La figura del doble se reitera en múltiples niveles; el Doppelgänger, como plantea Freud en sus aproximaciones a lo ominoso, produce la dislocadora sensación de aunar lo familiar con lo extraño, lo conocido con lo temido. El doble somos y no somos nosotros; es como si nos miráramos en esos gabinetes de espejos que nos devuelven una imagen transfigurada de nosotros mismos. Fascinados observamos eso que nos refleja; pues nos reconocemos y desconocemos al mismo tiempo. La novela de Donoso está llena de dobles, que se espejean, se atraen y rechazan; se necesitan, desean, aman, pero también se odian y repelen. El doble contiene simultáneamente lo deseado pero prohibido, lo inadmisible que no deja de aparecer bajo distintas formas. Las figuras del otro y de lo idéntico se fusionan. Se teme que el otro se imponga y se robe la propia identidad; pero esto es solo posible porque hay, en gran medida, una coincidencia que permitiría la sustitución. El rechazo así implica un movimiento contra sí mismo, un gesto que atenta contra el propio ser. El doble, por su lado, ese otro rechazado, toma forma en el Obsceno pájaro, entre otras, en las Viejas, esas mujeres relegadas ahora a las ruinas de un antiguo convento. Las viejas, cuando aún no lo eran, fueron las sombras de sus patrones, limpiándoles todas las manchas -reales y simbólicas- para que ellos pudieran sostener su imagen. “¿Cómo no van a tener a sus patrones en su poder si les lavaron la ropa, y pasaron por sus manos todos los desórdenes y las suciedades que ellos quisieron eliminar de sus vidas? [...] Desempeñando estos menesteres, las viejas fueron robándose algo integral de las personas de sus patrones al colocarse en su lugar para hacer algo que ellos se negaban a hacer" (Donoso 2016: 65). Tienen el poder de posicionarse en lo reprimido, y convertirse así en los fantasmas de quienes han vivido su vida negándolos.

Las viejas condensan en sí múltiples secretos, pero estos resultan imposibles de ser develados, pues, como las matrioskjas o las cajas chinas, quien busca llegar a una respuesta final solo se encontrará con otra capa más que funciona como nuevo revestimiento. Las viejas guardan cosas en cajitas, envueltas en trapos viejos y atadas con amarras. Pero al abrir las cajas, sacar el papel que sirve de protección, cortar las pitas que sujetan, solo se hallan objetos sin valor que no hablan, que no dicen nada. Tal como los secretos que las viejas se llevarán consigo a la muerte, la banalidad de las cosas que se encuentran escondidas solo apunta a la imposibilidad de la revelación:

Todo lo que usted encuentra está amarrado, empaquetado, envuelto en algo, dentro de otra cosa, ropa harapienta envuelta en sí misma, objetos trizados que se rompen al desenvolverlos, el asa de porcelana de una tacita de café, galones dorados de una cinta de Primera Comunión, cosas guardadas por el afán de guardar, de empaquetar, de amarrar, de conservar, esta población estática, reiterativa, que no le comunica su secreto a usted, Madre Benita, porque es demasiado cruel para que usted tolere la noción de que usted y yo y las viejas vivas y las viejas muertas y todos estamos envueltos en estos paquetes a los que usted exige que signifiquen algo porque usted respeta a los seres humanos. (35)

Las cosas, cajitas, paquetes operan como sinécdoque de las viejas, y estas, a su vez, como las portadoras de todos los secretos de las figuras que habitan el mundo donosiano. Las viejas -"las siete viejas del secreto" (67)- son peligrosas, porque ellas guardan todo lo desechado, todos los restos, lo que el mundo de la elite quiere alejar de sí: "Ellas conservan los instrumentos de la venganza porque van acumulando en sus manos ásperas y verrugosas esa otra mitad de sus patrones, la mitad inútil, descartada, lo sucio y lo feo que ellos, confiados y sentimentales les han ido entregando" (64). Pero 
las viejas terminan poseyendo mucho más que los pequeños y sucios secretos de los patrones, más que un conjunto de historias acerca de infidelidades, mentiras, engaños y traiciones. Encierran el secreto de los nombres y las identidades, encarnan la fusión de esas dos series que los patrones con desesperación pretenden mantener alejadas una de la otra. Pero sus necesidades y fragilidades los vuelven, una y otra vez, vulnerables. Es esta debilidad, que encierra la posibilidad de la destrucción, la que tienen bajo su poder las viejas. Y esta vulnerabilidad es la que está contenida en el secreto del nombre propio, y en el terror que se abre cuando se adquiere conciencia que detrás del nombre podría no haber nada.

Todas las identidades parecen intercambiables, todos los nombres se confunden y superponen, todo permanece, finalmente cerrado, como un imbunche ${ }^{6}$. El imbunche condensa en sí todos los movimientos que tienden a esconder y silenciar. Es un ser cerrado, cocido; cuerpo sin órganos: "Todo cosido, los ojos, la boca, el culo, el sexo, las narices, los oídos, las manos, las piernas" (64). El imbunche encierra para siempre todo en su hermetismo. Sin salida ni entrada, el imbunche es la claudicación total. Sin posibilidad de mirar, hablar, respirar, oír; de orinar, defecar, tener relaciones sexuales, el imbunche representa la paradoja de la muerte en vida. Vida imposible, cerrada sobre sí misma, el imbunche es el emblema del cierre definitivo. Cuerpo convertido en tumba. Así, El obsceno pájaro simboliza en el imbunche lo que en el plano de las representaciones espaciales y temporales tiene su correspondencia: tiempo cerrado al futuro, dado por un presente que no hace sino repetir una trama que ha sido escrita en el pasado; espacio que se reduce a dos casas que contienen en sí las coordenadas de lo posible. Las figuras repiten lo que antes de ellos han hecho otras; son marionetas de un relato cuyo desenlace está decidido de antemano. Nada nunca cambia, o toda transformación es solo una apariencia que esconde bajo su manto lo inmutable. La historia no es posible en la visión de esta novela de Donoso, pues para ello se requiere la posibilidad de que el tiempo pueda contener un transcurrir y que el espacio se abra para ser habitado. En la medida en que el imbunche es el modelo de este cierre, también simboliza la clausura del deseo. El deseo es movimiento, es fluir. En El obsceno pájaro, el deseo se trunca, al canalizar deseos cuyo origen está en otros. Iris Mateluna, que es prostituida y cuyos clientes deben usar un cartón, la cabeza de gigante; que se contornea bailando y está deseosa de sentir el rico Nanai que venden en su nombre, no deja de acostarse siempre con una marioneta; un cartón que emula un gigante. El deseo y la sexualidad se viven de forma desplazada; Azcoitía cree hacer el amor con su mujer Inés, pero en realidad penetra a Peta Ponce, su empleada; el mudito es quien tiene sexo con Inés, pero ella cree que lo hace con su marido. Las sustituciones identitarias se replican en el plano del deseo, lo que lo convierte en algo rechazado. Otra paradoja más, que se instala en las figuras fantasmales que pueblan la novela. Rechazo lo que deseo y por ello no me encuentro en mi deseo. Es por ello, que el gran secreto que articula toda la obra es el secreto del nombre propio. Ese nombre que ni siquiera quien lo porta conoce, lo que impide que se conecte con su propia verdad. La clínica del doctor Azula opera como otra sinécdoque para todo el mundo novelesco, pues ahí "fabrican seres que creen ser el mismo pero son otro o quizás otros, mezclan, revuelven, intercambian, todas las permutaciones son posibles en sus laboratorios blancos donde la unidad del ser no se respeta" (349). No se trata, sin embargo, de identidades fluctuantes que liberan de la tiranía del ser, sino de movimientos que cierran posibilidades y potencialidades para ser. Este repite, ciego y sin saber, cerrado a cualquier porvenir, trazos del pasado. Humberto, el mudito, el imbunche, el supuesto 
autor de las páginas que leemos, a pesar de haber repetido su nombre "nueve mil trescientas veces en los cien ejemplares de mi libro que conserva Don Jerónimo en su biblioteca entre las curiosidades bibliográficas que jamás nadie consulta" (117), lo olvida, debe confiar en su patrón "para que proteja mi nombre, para que esconda esas sílabas y ya nadie las recuerde salvo él, porque yo a veces me olvido, no existo, no tengo voz, no tengo sexo, soy la séptima vieja" (117). Un nombre oculto que podría prometer la develación de una historia que permanecerá secreta. Pues, como delira Humberto en sus escritos, "uno es lo que es mientras dura el disfraz" (140), no obstante, la amenaza aparece cuando se insinúa la posibilidad de que detrás del disfraz no hay nada.

\section{A modo de conclusión}

Novelas que se presentan de forma muy diferente, Zama y El obsceno pájaro revelan mundos imposibilitados; abierto y sin límites, uno; cerrado y colmado de límites, el otro. Espacio, tiempo y deseo se vuelven experiencias inhabitables; la vida de Zama se pasa, esperando algo que no llega, para terminar víctima de las violencias propias del mundo colonial; las vidas de los personajes de Donoso reiteran vivencias y afectos de otros, que muestran las brutalidades de la conformación social de las naciones del nuevo mundo. Conflictos presentes desde la historia colonial, que se perpetúan en las repúblicas de antaño y del presente.

41 La imagen inicial de Zama, aquella en la que aparece el mono muerto que gira, movido por corrientes que no logran alejarlo de la costa- reflejando especularmente el propio destino de Zama, quien no logra nunca la salida anhelada a Buenos Aires o a la península, condenado a Asunción del Paraguay-, revela un mundo estancado. Humberto Peñaloza, encerrado en el convento de la Chimba, convertido en una especie de muñeca de las viejas que lo vendan y vuelven su imbunche, es, de una forma similar, un ente que nos enrostra las ataduras a un pasado anclado en las relaciones de poder de la colonia. Las identidades posibles son siempre escurridizas, resistiéndose a ser sustentos potenciales para sujetos abiertos a un porvenir. Este último podría cifrarse en el secreto del nombre propio, que queda oculto entre las líneas de las novelas de Di Benedetto y Donoso. Los nombres no se encuentran nunca con lo nombrado y terminan siendo palabras vacías de cualquier significado. Más bien, operan confundiendo y desencontrando, enrostrando a los personajes su imposibilidad de ser alguien, de tener un sentido en las coordenadas históricas que habitan y constituyen. Nombres que, en lugar de posibilitar una identidad, la difuminan, devolviendo a las figuras una imagen deformada hasta la monstruosidad de sí mismas.

El secreto, tal como lo entiende Ricardo Piglia, es algo que alguien sabe y que no dice. Para Luisa Valenzuela, que sigue la mirada derridiana, el Secreto, en mayúscula, se vincularía con una cierta inadecuación estructural entre el lenguaje y la realidad, que convierte a la literatura en un lugar privilegiado de exploración de lo secreto, sabiendo de su imposible revelación. Las dos novelas que hemos analizado participan, así la propuesta inicial de esta lectura, de estos dos tipos de secretos. Ambas obras se colman de pequeños y sucios secretos -infidelidades, deseos prohibidos, saberes que otorgan poder sobre otros, traiciones-, pero entre o sobre ellos se encuentra la ominosa sospecha que hay algo que nunca podrá conocerse, porque no dejaría de remitir sino a sí mismo. En el caso de Zama, el texto opera desde su vaciamiento. El personaje se ve envuelto en un proceso continuo de despojamiento que se insinúa desde la imagen 
inicial del mono muerto, que queda dando vueltas y vueltas, y que culmina en el reflejo especular que se produce entre Zama y Vicuña Porto, y la muerte de Zama que adviene al final del texto. Si en la novela de Di Benedetto predomina la idea de una constante pérdida de cualquier asidero identitario, la novela de Donoso podría, en cierto sentido, entenderse desde sus procedimientos como un texto que funciona a la inversa. En lugar del despojo, la multiplicación. En lugar de la pérdida del sentido del nombre propio por su desvanecimiento, en El obsceno pájaro se duplican los nombres y las identidades una y otra vez. Máscaras, disfraces, operaciones; todo ser puede trocarse en otro, hasta hacer confusas todas las identidades. En las dos obras el efecto es similar: el nombre propio permanecerá secreto. La literatura solo puede acercársele y rodearlo para dar testimonio de su existencia y de su, a veces maravillosa y otras veces aterradora, inminencia.

\section{BIBLIOGRAFÍA}

Barthes, Roland, Fragmentos de un discurso amoroso, Madrid, Siglo XXI, 1997. Traducción de Eduardo Molina.

Bisama, Álvaro, "El terror" (Prólogo), José Donoso, El obsceno pájaro de la noche, Santiago de Chile, Alfaguara, 2016, p.9-14.

Derrida, Jaqcues y Ferraris, Maurizio, El gusto del secreto, Buenos Aires, Amorrortu, 2009. Traducción de Luciano Padilla López.

Di Benedetto, Antonio, Zama, Buenos Aires, Adriana Hidalgo, 2002.

Donoso, José, El obsceno pájaro de la noche, Santiago de Chile, Alfaguara, 2016.

Donoso, Pilar, Correr el tupido velo, Santiago de Chile, Alfaguara, 2009.

Hozven, Roberto, “Imbunche y majamama, dos archivos culturales chilenos, Atenea no. 506, diciembre 2012, Concepción, p. 153-169.

Magris, Claudio, El secreto y no, Madrid, Anagrama, 2017. Traducción de Pilar González Rodríguez. Néspolo, Jimena, Ejercicios de pudor. Sujeto y escritura en la narrativa de Antonio de Benedetto, Buenos Aires, Adriana Hidalgo, 2004.

Piglia, Ricardo, “Secreto y narración", La forma inicial. Conversaciones en Princeton, Buenos Aires, Eterna Cadencia, 2015, p.249-260.

Premat, Julio, “Así se nace. Vanguardia, estilo, extrañeza en Di Benedetto”, Liliana Reales (ed.), Homenaje a Antonio Di Benedetto, 2017, Web. Consultado el 3 de diciembre de 2021.

Saer, Juan José, “Zama”, El concepto de ficción, Buenos Aires, sexi Barral, 2014, p. 44-50.

---, “Antonio de Benedetto", El concepto de ficción, Buenos Aires, sexi Barral, 2014, 51-43

Valenzuela, Luisa, Escritura y secreto, Madrid, FCE, 2003. 


\section{NOTAS}

1. Este artículo forma parte del Proyecto Fondecyt Regular № 1210310, titulado "Literaturas del secreto".

2. Por una serie de referencias indirectas, el lector puede configurar el mapa que se traza en las páginas del libro, pero nunca se dice explícitamente que la ciudad, algo fantasmagórica y descentrada, en la que se encuentra Zama, es Asunción del Paraguay, lo que agrega un grado de abstracción e incertidumbre a los paisajes que forman el escenario de la novela. De esta forma, el espacio en el que transcurre la novela se conforma más como un paisaje mental que como referencia a un lugar "real".

3. Juan José Saer postula, a partir de su lectura de Zama, que "[t]oda narración transcurre en el presente, aunque habla, a su modo del pasado. El pasado no es más que el rodeo lógico, e incluso ontológico, que la narración debe dar para asir, a través de lo que ha permitido, la incertidumbre frágil de la experiencia narrativa, que tiene lugar, del mismo modo que su lectura, en el presente. Al hacer más evidente ese pasado, al convertirlo en pasado crudo, nítidamente alejado de la experiencia narrativa, el narrador no quiere sino sugerir la persistencia histórica de ciertos problemas" (2014: 46). Saer vincula acá el tiempo de la narración con el tiempo histórico, superponiendo, de esta forma, la reflexión que el texto impulsa simultáneamente sobre el acto de narrar y el transcurrir histórico.

4. Saer rapara en esta pérdida de una ilusión que haga posible una identidad, producida en la novela de Di Benedetto. Repara en el estilo, aparentemente sencillo de relatar del autor, para luego plantear que "esa simplicidad narrativa es engañosa: una y otra vez, la narración lineal es interferida por breves historias, alegorías, metáforas, que anulan la ilusión biográfica e instalan el conjunto de lo narrado en una dimensión mítica." Luego agrega que es "como su instintivamente el narrador supiese que no vivimos nuestra vida más que al margen de los acontecimientos y superponiendo a nuestra experiencia la reflexión confusa sobre sus sentidos posibles" (Saer 2014: 48)

5. Julio Premat lee la obra de Di Benedetto, y en especial Zama, en relación con una cierta extrañeza y particularidad de la escritura del autor, que más que inaugurar una forma narrativa vanguardista y experimental desembocarían en una visión pesimista y melancólica. La escritura de Di Benedetto tendría que ver, para Premat, con la constatación ineludible de un límite, que puede ser descrito desde "la impotencia enigmática del sujeto ante lo real" (18). El nombre propio al que hacía alusión arriba se estrella, en la medida de su dimensión secreta imposible de develar, contra esta frontera, en la que no puede dilucidarse el vínculo entre el lenguaje y lo que nombra. Premat habla de "una dimensión desconocida" y de que, al acercarse a la obra Di Benedetto, "hay que saber que la interpretación integra un límite o un espacio incógnito" (Premat 2017: 19). Una de las ideas con las que concluye su propuesta de aproximación a un autor que se considera comúnmente como "raro", es que el proceso de despojamiento posible de advertir en sus obras "es argumental, temático, simbólico y discursivo. Los silencios, omnipresentes, no sugieren contenidos velados, sino lo incognoscible, lo indecible" (23-24). Los secretos, como los silencios, no son descubribles, pues, en última instancia, tal como el secreto del nombre propio, chocan con una barrera no traspasable. Como aquel momento donde el nombre parece no remitir a nada más que a sí mismo.

6. El imbunche (también invunche) es un ser mitológico que proviene de la cultura mapuche y la mitología chilota. El nombre, del mapundung, significa "persona deforme". Se trata de una criatura que tiene la cabeza doblada hacia atrás, los brazos, los dedos, la nariz, la boca y las orejas torcidos, así como una lengua bipartita. Suele andar en una sola pierna por tener la otra pierna pegada por detrás al cuello o la nuca. No puede hablar, y solo emite sonidos guturales. Donoso, entonces, retoma esta figura de la mitología indígena del territorio chileno y propone, de este modo, también desde aquí, una reflexión sobre los lazos negados con le mundo d las culturas 
originarias. Véase para una revisión de la figura del imbunche en el "archivo nacional", el artículo "Imbunche y majamama, dos archivos culturales chilenos" (2012) de Roberto Hozven. En El obsceno pájaro las viejas "imbunchan" al mudito, para, como lo hacen con sus paquetes y cajas, ocultar todos los secretos en él, sin posibilidad de fuga.

\section{RESÚMENES}

El escritor argentino Antonio di Benedetto y el autor chileno José Donoso escribieron gran parte de su obra más importante entre finales de los cincuenta y fines de los setenta del siglo XX. Los dos vivieron largos períodos de su vida fuera de sus países de origen, y ambos, de formas muy distintas y por razones diversas, entraron en una relación más bien tensa con los autores del boom. A pesar de estas coincidencias, no suelen ser escritores que se lean de forma cruzada. Lo que este artículo propone es una aproximación a Zama (1956) de Di Benedetto y El obsceno pájaro de la noche (1970) a partir de la figura del secreto del nombre propio, para observar de qué forma, en los dos textos, se produce la amenaza de una identidad tanto personal como histórica, a partir del desdibujamiento de los posible sentidos que puede otorgar el nombre propio. Este se cifra en un secreto que no puede ser resuelto y que termina por proponer una reflexión sobre la literatura misma.

L'écrivain argentin Antonio di Bendetto et le chilien José Donoso ont écrit une grande partie de leurs œuvres les plus importantes entre la fin des années 1950 et la fin des années 1970. Tous les deux ont vécu pendant longue périodes de leurs vies en dehors de ses pays d'origine, et tous deux, de manière très différente et pour des raisons bien divergentes, ont eu un rapport plutôt difficile avec les auteurs du boom. Malgré ces coïncidences, il ne s'agit pas des auteurs qu'ont été lu ensemble. Nous proposons alors de tenter une approximation de Zama (1956) et de L'Obscène Oiseau de la nuit (1970) à partir de la figure du secret du nom propre. Il s'agit d'analyser comment, dans les deux textes, il y a une menace qui se pose sur l'identité, aussi bien individuelle qu'historique, fondée sur la difficulté d'apprendre les significations liées au nom propre. Celui-ci est pris dans un secret qui ne peut être résolu et qui finit par proposer ainsi sur la littérature ellemême.

The Argentinian writer Antonio di Benedetto and the Chilean author José Donoso wrote the most important part of their works between the end of the fifties and the end of the seventies of the XX Century. Both lived long periods of times out of their home countries, and both -in different ways and for different reasons- had a mostly tense relationship with the authors of the Boom. Despite these coincidences, it is not very common to read them in dialogue. This article proposes to approach Di Benedetto's Zama (1956) and Donoso's The Obscene Bird of the Night (1970), parting form the figure of the secret of the proper name, to observe in which form, in both texts, the personal and historical identity is threatened. The possible senses which can be related to the proper name suffer a process of dissolution. The proper name is embedded in a secret that cannot be resolved and which reflects on literature itself. 
ÍNDICE

Palabras claves: Antonio Di Benedetto, José Donoso, secreto, nombre propio

Keywords: Antonio de Benedtto, José Donoso, Secret, Proper Name

Mots-clés: Antonio Di Benedetto, José Donoso, secret, nom propre

\section{AUTOR}

ANDREA KOTTOW

Universidad Adolfo Ibáñez

andrea.kottow@uai.cl 